\title{
Enhancement of Nucleate Pool Boiling Heat Transfer with Sodium Oleate
}

\author{
K. M. Tanvir Ahmmed and Sultana Razia Syeda* \\ Department of Chemical Engineering, Bangladesh University of Engineering and Technology, BUET, Dhaka, \\ 1000, Bangladesh, *Email: syedasrazia@che.buet.ac.bd

\begin{abstract}
:
In this study saturated nucleate pool boiling of water with sodium oleate surfactant on a horizontal cylindrical heater surface has been investigated experimentally and compared with that of demineralized water. The concentration of sodium oleate in water was 100-300 ppm. The experimental results show that a small amount of surfactant enhances the heat transfer coefficient significantly. At low surfactant concentrations, heat transfer coefficient increases with increasing surfactant concentration in water. The maximum heat transfer enhancement is found to be at $250 \mathrm{ppm}$ of sodium oleate solution. By adding more surfactant to water, heat transfer coefficient is found to be lowered. Surface tension of different concentration of sodium oleate solutions is measured. It is observed that the maximum heat transfer coefficient is obtained at a surfactant concentration that corresponds to
\end{abstract} \\ the critical micelle concentration $(\mathrm{cmc})$ of the sodium oleate solution.
}

Keyword: Nucleate pool boiling, enhanced heat transfer, surfactant, surface roughness, surface tension

\section{Introduction}

Boiling heat transfer is considered as the most convenient means of transferring large amount of heat in many applications. In boiling heat transfer, it is usually desirable to transfer the largest possible amount of heat with the smallest possible temperature difference between the heating surface and the boiling liquid, and to maximize the critical heat flux. Study of the enhancement of boiling heat transfer has become one of the fastest growing research areas of recent years [1]. This growth has been driven by the need to improve boiling heat transfer in high heat-flux devices (for example, in electronic component cooling) and in reducing the size and cost of equipment in chemical, refrigeration, and other types of plants. Various enhancement techniques have been developed over the past decades to fulfill these criteria [2,3]. Among the different techniques, addition of surfactant (as a passive technique) was found to be the most viable and attractive for further research [4].

Addition of small amount of surfactant to liquid, as an enhancement technique, shows a significant enhancement in pool boiling heat transfer $[5,6,7,8]$. The effect of surfactants, such as, Alkyl (8-16) Glycoside, Sodium lauryl sulfate, Habon G, Triton X-100 etc. have been studied in the past $[9,10,11]$. The effect of surfactant additives on nucleate boiling heat transfer is complex. A solution of a surface-active solute boils very differently from that of a pure liquid having same surface tension. The surfactant affects the surface property of the heating element as well as the bubble behavior. Surface tension, kinematic viscosity, Surface wettability, Dynamic surface effect, dynamic spreading coefficients etc. are some of the parameters considered by different researchers to explain the boiling enhancement in presence of surfactant. The current state of research is far from a systematic theory or explanation for the enhancement of boiling heat transfer caused by surfactant additives. Besides, there is an ongoing search for surfactants for effective enhancement of pool boiling heat transfer. However, only tentative criteria for a given surfactant as a competent additive in enhancing nucleate boiling heat transfer of water are available at present. The recent state of the art review by Cheng et al. concluded that experiments of nucleate pool boiling of aqueous surfactant solution should be further emphasized to understand the boiling phenomena [12].

The objective of this work is to carry out pool boiling experiments in solutions of sodium oleate and interpret the boiling behavior by analyzing the physical properties of the boiling system. Surface roughness of the heater, surface tension of the solution and viscosity data are used for interpreting the experimental results. The analysis on experimental results for sodium oleate solution is also compared with Sodium dodecyl sulfate (SDS) and Habon G.

\section{Experimental}

\subsection{Instruments and Chemicals}

A schematic diagram of the experimental setup used in this study is shown in Figure 1. A cartridge type electric heater is placed in a glass column having $17.8 \mathrm{~cm}$ outer diameter and $40.6 \mathrm{~cm}$ height. The heater surface is illuminated, and is photographed from outside of the glass column. The non-heated part of the heater is placed in a Teflon rod. This placement reduced strain on the lead wire. The cartridge heater is made of a seamless stainless steel tube having $1.27 \mathrm{~cm}$ outer diameter and $12.5 \mathrm{~cm}$ length. The $220 \mathrm{~V}, 1400 \mathrm{~W}$ heater is supplied by Rotterdamse Elementen Fabriek of Netherlands. It provided a peak heat flux of about 335 $\mathrm{kW} / \mathrm{m}^{2}$. The junction of the thermocouple is placed at the central position of the sheath's internal surface. As the heater is sufficiently long and thin, the heat conduction in the axial direction can be neglected.

\footnotetext{
Corresponding Author: Sultana Razia Syeda

E-mail: syedasrazia@che.buet.ac.bd
} 


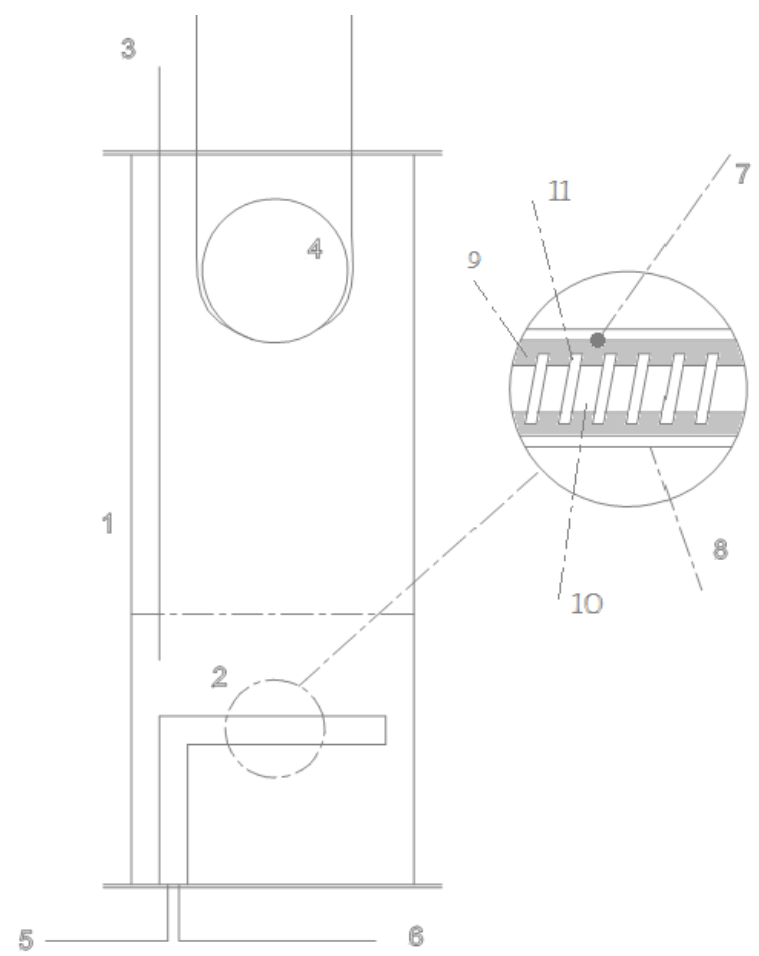

Figure 1 Schematic of pool boiling apparatus: (1) glass column vessel; (2) heating element with provision for surface temperature measurement; (3) temperature probe for bulk fluid temperature measurement; (4) water-cooled condenser coil; (5) thermocouple to digital meter; (6) AC power supply; (7) thermocouple junction; (8) stainless steel tube; (9) insulation powder; (10) ceramic core; (11) heating coil

The pool temperature is measured by a calibrated thermocouple-digital readout meter. A mercury manometer is used to monitor the pool pressure throughout the experiment. A coiled-tube water-cooled condenser is provided for condensing the generated vapor and returning the condensed liquid into the pool. Rate of water flow through the condenser is controlled by manual valve to maintain atmospheric pressure in the pool. As the amount of subcooled returned condensate is very small in comparison to the amount of saturated liquid in the vessel, the return of the liquid condensate has no or little effect on the pool liquid temperature.

A variac-controlled AC power supply, a panel voltmeter, a clamp meter, and an electricity meter provided the necessary controls and measurements of the input electric power during the experiment.

The sodium oleate (General Purpose Reagents) is supplied by BDH Laboratory Supplies, UK. This anionic surfactant is a component of commercial soaps and is soluble in water.

As the surface roughness of the heater surface significantly influences the boiling characteristics, it is measured with Surtronic 25 roughness checker (Taylor Hobson Precision, USA). Several scans are performed to determine the arithmetic mean deviation roughness $\left(R_{a}\right)$ of the surface. For this heater surface, it is found to be $1.54 \mu \mathrm{m}$. Optical microscope images of the roughness characteristics of heater surface is also captured and shown in Figure 2. This image clearly shows a random distribution of cavities, pits and grooves of different shapes and sizes throughout the surface of the heater.

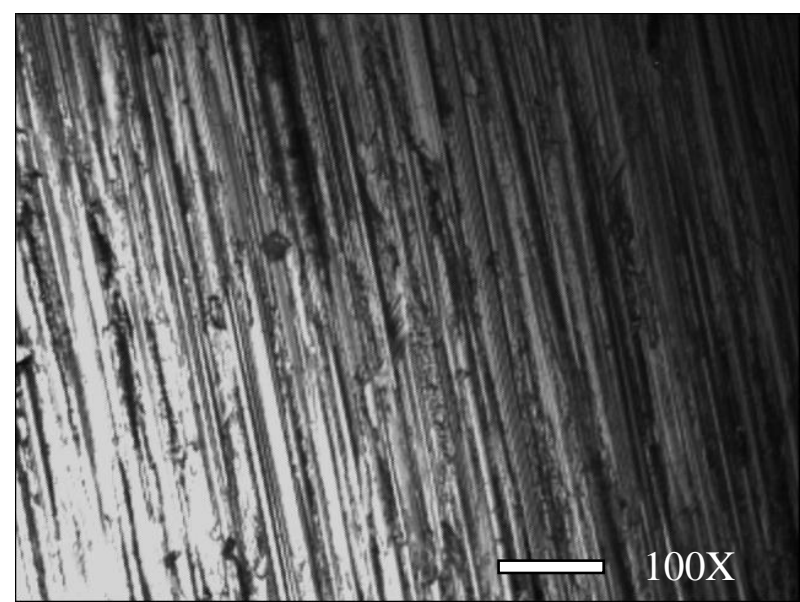

Figure 2 Optical microscope image of the roughness characteristics of heater surface.

The boiling curve for water is established over two month's period to check the repeatability and aging effect of the heater. For each boiling test run, the column is loaded with $2000 \mathrm{ml}$ of liquid to bring the liquid surface to a level of $60 \mathrm{~mm}$ above the heater surface. After achieving the liquid saturation temperature, the test is carried out by varying the wall heat flux in a stepwise manner. Surfactant solutions are replaced by demineralized water in between two test runs. This precaution validates the experimental reliability of the apparatus.

\subsection{Surface Tension Measurements}

In this work, a CSC - 70535 DuNouy Precision Tensiometer (CSC Scientific Company, Inc., Fairfax, VA) with a platinum-iridium ring is used for the equilibrium surface tension measurements. This tensiometer uses a fine torsion wire for applying the necessary force required to withdraw the ring from the surface of the liquid under test. Measurements for sodium oleate solutions are carried out at $28^{\circ} \mathrm{C}$.

Sodium oleate solutions of different concentrations are prepared by dissolving weighed samples in demineralized water. The physico-chemical properties of the surfactant powder are listed in Table 1.

Table 1 Physico-chemical properties of Sodium Oleate

\begin{tabular}{cc}
\hline Chemical formula & $\mathrm{C}_{18} \mathrm{H}_{33} \mathrm{NaO}_{2}$ \\
\hline Ionic type & anionic \\
Appearance & Brownish-white \\
Molecular weight & 304 \\
Water solubility & $100 \mathrm{~g} / \mathrm{l}(100,000 \mathrm{ppm})$ \\
\hline
\end{tabular}


The tensiometer is initially calibrated using demineralized water at room temperature. Then, by comparing the established value of surface tension of water from literature the validity of measurements are established. The accuracy of the measurements is within $\pm 0.5 \mathrm{mN} / \mathrm{m}$. The equilibrium surface tension data for sodium oleate solutions at $28^{\circ} \mathrm{C}$ are shown in Figure 3. Surface tension decreases asymptotically with increasing concentration. The asymptotic limit is termed as the critical micelle concentration $(\mathrm{cmc})$ of the surfactant. For sodium oleate solution, it is found that the $\mathrm{cmc}$ is about $230 \mathrm{ppm}$.

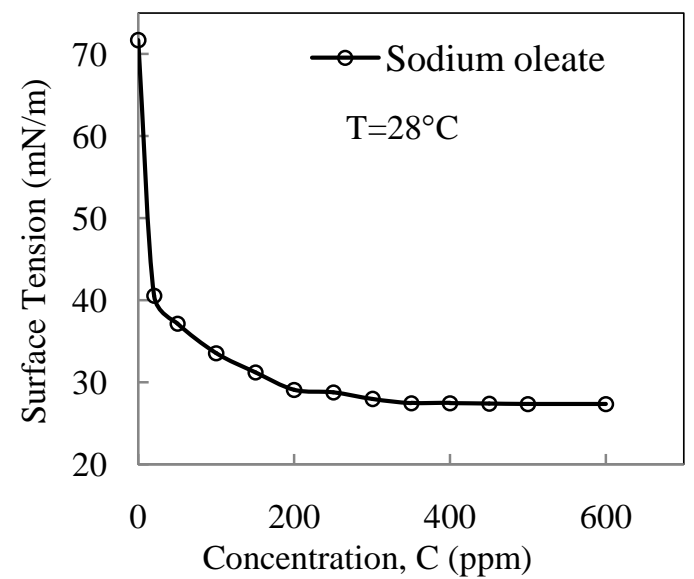

Figure 3 Equilibrium surface tension measurements for Sodium oleate solutions.

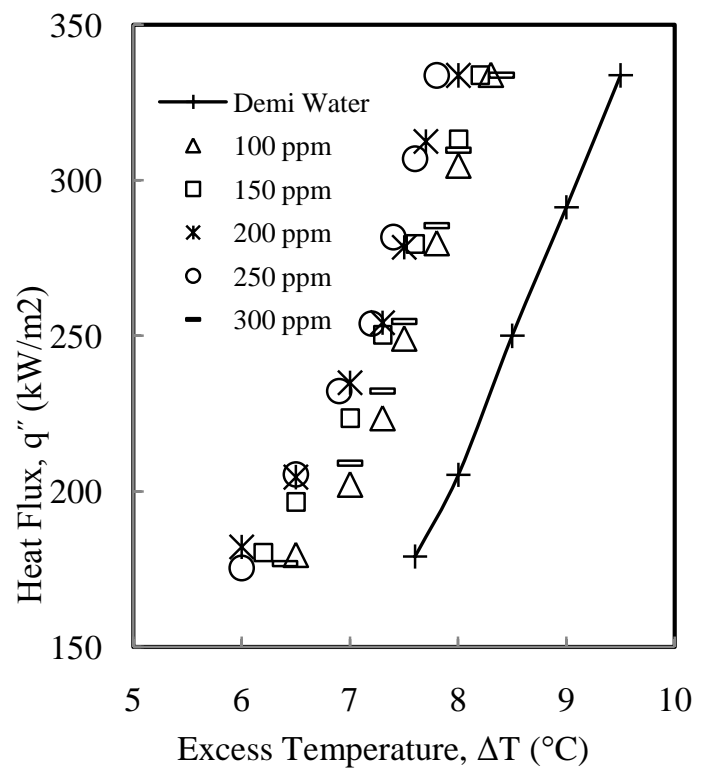

Figure 4 Nucleate Pool boiling data for water and water with sodium oleate at $1 \mathrm{~atm}$.

\section{Results and Discussion}

The saturated nucleate pool boiling data for water and water with different concentrations of sodium oleate are plotted in Figure 4. Boiling data of surfactant solutions lie to the left of the boiling curve of pure water, which is an indication of heat transfer enhancement. For increasing and decreasing heat fluxes same measurements of excess temperature are observed.

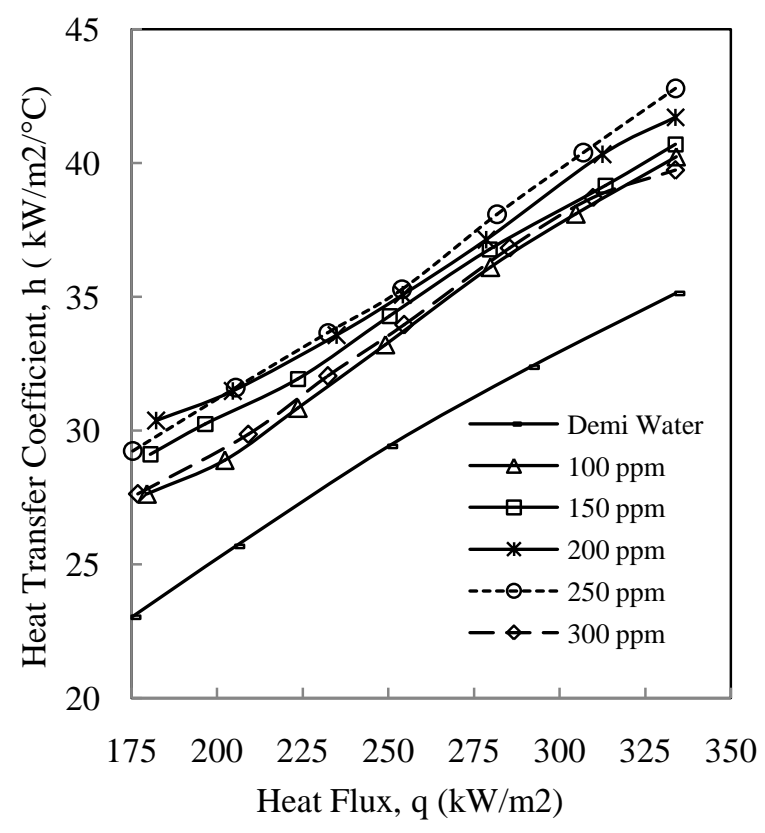

Figure 5 Effect of sodium oleate concentration on nucleate pool boiling heat transfer coefficient of sodium oleate solution.

The influence of heat flux and surfactant concentration on the nucleate pool boiling heat transfer rate of sodium oleate solutions is more evident in Figure 5, where experimental data are expressed as a plot of heat transfer coefficient versus heat flux. The heat transfer increases with increasing the solution concentration, and it reaches maximum when sodium oleate concentration is $250 \mathrm{ppm}$. Further addition of surfactant to water decreases the heat transfer coefficient.

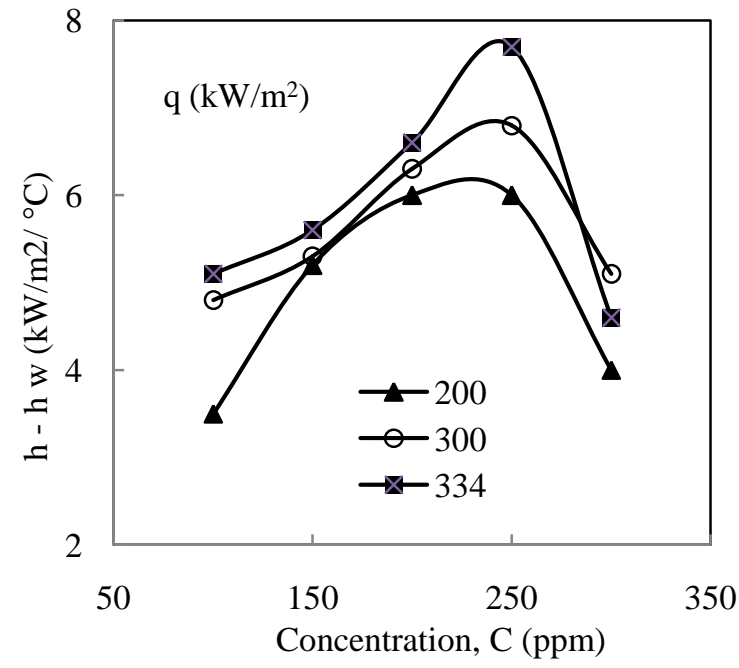

Figure $6\left(h-h_{w}\right)$ as a function of concentration of sodium oleate solutions.

The enhancement of heat transfer by adding surfactant can be shown by the difference, $\left(\mathrm{h}-\mathrm{h}_{\mathrm{w}}\right)$, where $\mathrm{h}$ and 
$h_{w}$ are boiling heat transfer coefficients for surfactant solutions and pure water respectively. $\left(h-h_{w}\right)$ as function of surfactant concentration with heat flux as a parameter is shown in Figure 6. The heat transfer coefficient increases with increasing the solution concentration and reaches a maximum value at 250 ppm, and decreases with further increasing the solution concentration.

An explanation for the observed enhancement in pool boiling heat transfer coefficient seen in Figure 6 can be given by considering the effect of equilibrium surface tension and dynamic viscosity of sodium oleate solution. It is confirmed that the small decrease in surface tension causes large increase in the number of nuclei [12].

$$
n \propto e^{-\sigma^{3}}
$$

Eq. (1) states that decrease in surface tension increases the rate of nucleus formation which in turn affects the heat transfer rate. Eq. (2) is one of the relations which indicate an influence of viscosity on heat transfer coefficient [13].

$$
h \propto q^{\prime m} \mu^{\mathrm{n}}
$$

The value of viscosity exponent ranges from 0 to -1.4 .

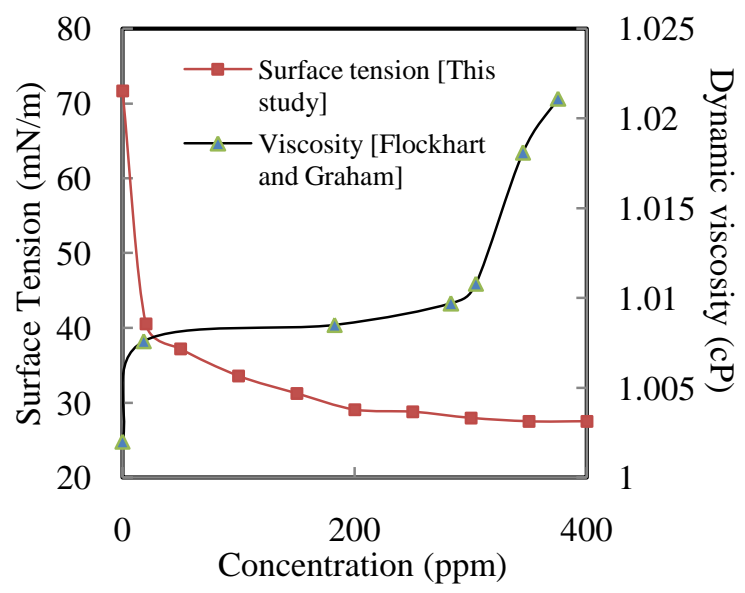

Figure 7 The surface tension (at, $28^{\circ} \mathrm{C}$ ) and, dynamic viscosity (at $20^{\circ} \mathrm{C}$ ) as a function of sodium oleate concentration. (viscosity values are adapted from [15])

Figure 7 is a plot of surface tension and viscosity as a function of surfactant concentration. From this plot it is obvious that beyond $250 \mathrm{ppm}$ the viscosity increases sharply. But, the surface tension depression is nearly absent in this region.

The joint effect of surface tension and viscosity can be explained by Marangoni effect. When an interface expands locally, surface active solutes are swept outward with the movement, creating a gradient in their concentration. This concentration gradient implies a surface tension gradient which acts opposite to the movement. The interfacial movement is therefore damped. Consider a fluid zone of thickness d across which the surface tension difference is $\Delta \sigma$.
The Marangoni number,

$$
M a=\frac{\Delta \sigma \cdot \mathrm{d}}{\mu \mathrm{k}}
$$

is the controlling parameter of interfacial flow driven by the surface tension gradient $(\Delta \sigma)$ that affects the heat transfer coefficient [14].

The Marangoni number can also be expressed as,

$$
M a=\text { Re. } \operatorname{Pr}
$$

Where,

$R e=\frac{\Delta \sigma \cdot \rho \mathrm{d}}{\mu^{2}}$ and $\operatorname{Pr}=\frac{\mathrm{c \mu}}{\mathrm{k}}$ are the Reynolds number and Prandtl number, respectively.

The value of density $(\rho)$, specific heat (c), and thermal conductivity $(\mathrm{k})$ of water and water with surfactant are same as the very small amount of surfactant does not affect these properties. So, the parameters that can change are surface tension and viscosity. From, Figure 7 , at low concentration the viscosity almost does not change, so Prandtl number also does not change. But, Reynolds number increases with surface tension depression. Such a behavior of dimensionless number explains the increase in heat transfer coefficient.

But, at higher concentration (beyond $250 \mathrm{ppm}$ of sodium oleate), surface tension depression is ceased to change further, whereas, viscosity increases with increasing surfactant concentration. It increases the Prandtl number proportional by to the viscosity $\mu$, whereas it decreases the Reynolds number proportional by $\mu^{2}$. So, the Marangoni effect acts in the opposite direction and suppresses the boiling heat transfer. This explanation is in qualitative agreement with Hetsroni et al. experiments with Habon G surfactant [14].

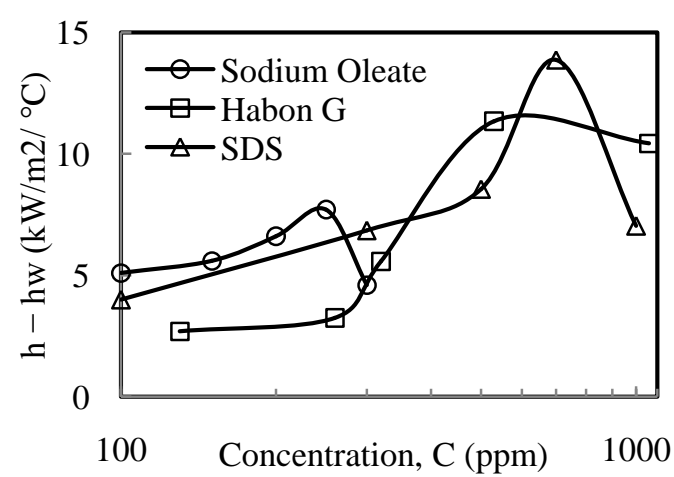

Figure $8\left(\mathrm{~h}-\mathrm{h}_{\mathrm{w}}\right)$ for various surfactant solutions as a function of surfactant concentration (Habon G and SDS at $400 \mathrm{~kW} / \mathrm{m}^{2}[6,14]$ heat flux and Sodium Oleate at $\left.334 \mathrm{~kW} / \mathrm{m}^{2}\right)$.

Data of this study for transferring maximum amount of heat with a certain concentration of surfactant $(250 \mathrm{ppm}$ sodium oleate) is in qualitative agreement with boiling heat transfer data published by Tzan and Yang, and Hetsroni et al. [6,14]. This comparison is shown in Figure 8. They reported that nucleate boiling heat transfer decreases when the concentration of sodium 
dodecyl sulfate (SDS) solution was higher than 700 ppm, and when the concentration of Habon G solution was higher than $530 \mathrm{ppm}$. It is noted that SDS is an anionic surfactant while Habon $G$ is a cationic surfactant.

The heat transfer enhancement for sodium oleate is lower than that of other two surfactant solutions. The reason is that this study used a rough surface which already enhanced the heat transfer coefficient for demineralized water. If the heater surface was polished then the enhancement due to surfactant would be more prominent.

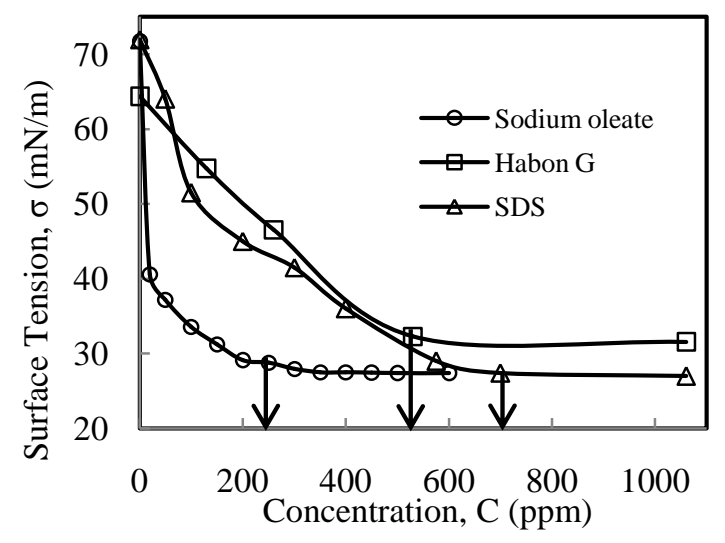

Figure 9 Surface tension versus concentration curves showing approximate critical concentrations [5, 57].

In Figure 9 surface tension depression with surfactant concentration for Sodium oleate, Habon G and SDS are plotted. For Habon G, SDS and Sodium oleate the cmc is at $530 \mathrm{ppm}, 700 \mathrm{ppm}$ and $250 \mathrm{ppm}$ respectively. From this figure it is clear that the maximum amount of enhancement is at or near the cmc of these surfactant solutions.

\section{Conclusion}

Maximum nucleate pool boiling heat transfer enhancement occurred at or near the critical micelle concentration. Addition of more sodium oleate beyond this concentration lowers the heat transfer coefficient. This observation validates the results obtained by the previous researcher's by using SDS and Habon G surfactant. Boiling behavior of water with sodium oleate solution at $\mathrm{cmc}$ can be explained qualitatively with surface tension and viscosity in terms of Marangoni number. However, it was not conclusive as other parameters such as contact angle, dynamic spreading coefficient etc. may play role in enhancement. Further investigation is needed to understand the phenomenon better.

\section{References}

1. Hewitt, G. F., Boiling in W. M. Rohsenow, J. P. Hartnett and Y. I. Cho (eds.). Handbook of Heat Transfer, chap. 15, pp. 1-168, McGraw-Hill, New York, 1998.
2. Bergles, A. E., Jensen, M. K., and Shome, B., The Literature of Enhancement of Convective Heat and Mass Transfer, J. Enhanc. Heat Transfer, vol. 4, (1-6), 1996.

3. Bergles, A. E., Some Perspective on Enhanced Heat Transfer-Second Generation Heat Transfer Technology, $J$. Heat Transfer, vol. 110, pp. 1082-1096, 1998.

4. Yang, Y. M., and Maa, J. R., On the Criteria of Nucleate Pool Boiling Enhancement by Surfactant Addition to Water, Trans IChemE, vol. 79, (Part A), pp. 409-416, 2001.

5. Yang, Y. M., and Maa, J. R., Pool boiling of dilute surfactant solutions, ASME Journal of Heat Transfer, vol. (105), pp. 190-192, 1983.

6. Tzan, Y. L., and Yang, Y. M., Experimental Study of Surfactant Effects on Pool Boiling Heat Transfer, ASME Journal of Heat Transfer, vol. 112, pp. 207-212, 1990.

7. Wasekar, V. M., and Manglik, R. M., Pool Boiling Heat Transfer in Aqueous Solutions of an Anionic Surfactant, ASME Journal of Heat Transfer, vol. 122, pp. 708-715, 2000.

8. Hetsroni, G., Gurevich, M., Mosyak, A., Rozenblit, R., and Segal, Z., Boiling Enhancement with Environmentally Acceptable Surfactants, International Journal of Heat and Fluid Flow, vol. 25, pp. 841-848, 2004.

9. Wasekar, V. M., and Manglik, R. M., A Review of Enhanced Heat Transfer in Nucleate Pool Boiling of Aqueous Surfactant and Polymeric Solutions, Journal of Enhanced Heat Transfer, vol. 6, pp. 135-150, 1999.

10. Wasekar, V. M., Heat Transfer in Nucleate pool Boiling of Aqueous SDS and Triton X-100 Solutions, Heat Mass Transfer, vol. 45, pp. 1409-1414, 2009.

11. Hetsroni, G., Gurevich, M., Mosyak, A., and Rozenblit, R., Effect of Surfactant Concentration on Saturated Flow Boiling in Vertical Narrow Annular Channels, International Journal of Multiphase Flow, vol. 33, pp. 1141-1152, 2007.

12. Cheng, L., Mewes, D., and Luke, A., Boiling Phenomena with Surfactants and Polymeric Additives: A State-of-theart Review, International Journal of Heat and Mass Transfer, vol. 50, pp. 2744-2771, 2007.

13. Peyghambarzadeh, S. M., Jamialahmadi, M., Alavi Fazel, S. A., and Azizi, S., Experimental and Theoretical Study of Pool Boiling Heat Transfer to Amine Solutions, Brazilian Journal of Chemical Engineering, vol. 26, (1), pp. 33-43, 2009.

14. Hetsroni, G., et al., The Effect of Surfactants on Bubble Growth, Wall Thermal Patterns and Heat Transfer in Pool Boiling, International Journal of Heat and Mass Transfer, vol. 44, pp. 485-497, 2001.

15. Flockhart, B. D., and Graham, H., Study of Dilute Aqueous Solutions of Sodium Oleate, Journal of Colloid Science, vol. 8, (1), pp. 105-115, 1953.

\section{Nomenclature}

$\begin{array}{ll}\mathrm{C} & \text { concentration, } \mathrm{ppm} \\ \mathrm{c} & \text { specific heat, } / \mathrm{kg} \cdot \mathrm{K} \\ \mathrm{d} & \text { diameter, } \mathrm{m} \\ \mathrm{h} & \text { heat transfer coefficient, } \mathrm{W} / \mathrm{m}^{2} . \mathrm{K} \\ \mathrm{k} & \text { thermal conductivity, } \mathrm{W} / \mathrm{m} \cdot \mathrm{K} \\ \mathrm{q}^{\prime \prime} & \text { heat flux, } \mathrm{W} / \mathrm{m}^{2} \\ \mu & \text { dynamic viscosity, } \mathrm{cP} \\ \rho & \text { density, } \mathrm{kg} / \mathrm{m}^{3} \\ \Delta \mathrm{T}_{\mathrm{e}} & \text { excess temperature, } \mathrm{K} \\ \sigma & \text { surface tension, } \mathrm{mN} / \mathrm{m}\end{array}$

